\title{
"Grafiteras, negras y lesbianas": la escritura de grafitis feministas en la ciudad de Salta, Argentina
}

\section{"Graffiti, black and lesbian writers": the writing of feminist graffiti in the city of Salta, Argentina}

Cinthia Natalia Gonza*

\section{Resumen}

El presente artículo muestra parte de las transformaciones que introduce la escritura de grafitis feministas en la ciudad de Salta- Argentina, y la manera en la que éstos componen un nuevo y alternativo repertorio visual en el paisaje urbano. Los grafitis feministas y transfeministas refieren a aquella escritura anónima sobre paredes y calles del espacio urbano, cuyo contexto de emergencia remite a las movilizaciones organizadas por agrupaciones feministas. Analiza desde un enfoque interseccional y desde una perspectiva de género, aquellos procesos sociales de construcción y diferenciación espacial en la ciudad y las relaciones de poder que los atraviesan. Busca aportar, en constante diálogo con los estudios comunicacionales de la ciudad y el grafiti, a la comprensión de los usos diferenciados que las mujeres, lesbianas e identidades transgénero hacen del espacio.

Palabras clave: ciudad, comunicación, grafitis y género.

\section{Abstract}

The article shows part of the transformations that feminist graffiti writing introduces in the city of Salta-Argentina, and how these make up a new and alternative visual repertoire in the urban landscape. Feminist and transfeminist graffiti refer to that anonymous writing on walls and streets of urban space, whose emergency context refers to the mobilizations organized by feminist groups. It analyzes from an intersectional approach and a gender perspective, those social processes of construction and spatial differentiation in the city, and the power relations that cross them. It seeks to contribute, in constant dialogue with the communicational studies of the city and graffiti, to the understanding of the differentiated uses that women, lesbians, and trans identities make of space.

Keywords: city, communication, graffiti and gender.

Fecha de recepción: 14 de junio de 2019 • Fecha de aceptación: 03 de Enero de 2020 * Doctora en Ciencias Sociales. Facultad de Humanidades-Universidad Nacional de Salta. Correo electrónico: cinthianata@
gmail.com 


\section{Introducción}

Este artículo se enmarca dentro de una tesis de investigación doctoral que parte del interés por la ciudad escrita, escrachada: la ciudad manchada. Es también la ciudad apropiada, sensible, parlante y móvil. Mira allí la experiencia de los cuerpos, las palabras y las imágenes. Observa y retrata la trayectoria y el desplazamiento escrito sobre las paredes a mano alzada, de mujeres, lesbianas y transgénero (en adelante trans). La investigación analiza aquellos procesos sociales de construcción y diferenciación espacial en la ciudad de Salta desde una perspectiva de género y busca contribuir desde allí, en constante diálogo con los estudios comunicacionales de la ciudad y el grafiti, con la comprensión de los usos diferenciados que las mujeres e identidades disidentes hacen del espacio urbano. También analiza y estudia las diferentes configuraciones de "feminidades" y "otredades" que se materializan en el espacio a partir de los grafitis presentes en el micro centro de la ciudad de Salta, contemplando para ello, el contenido de estos mensajes y los relatos que les actores involucrados habilitan sobre esta práctica.

Desde ese marco, se analiza algunos elementos del relato-sanción "Esas no son mujeres" presente en redes sociales y en medios de comunicación cuando se hace referencia a quienes pintan grafitis feministas y transfeministas. Transfeminista $y$ transfeminismo son categorías que emergen de los relatos de les graffiteras y desde allí, se articula en esta propuesta como una herramienta epistemológica que busca pensar los diversos estados de tránsito de género, de migración, de mestizaje, de vulnerabilidad, de raza y de clase, con el fin de abrir espacios y campos discursivos a todas aquellas prácticas y sujetos de la contemporaneidad que no son considerados de manera directa por el feminismo hétero, blanco, biologiscista e institucional (Sayak, 2018).

El artículo también ofrece una reflexión en torno a no ser mujer, no- mujer, como otra de las categorías que se recoge y se repone de los relatos de las grafiteras, en donde se construye como una forma de identidad estético política, no biologicista, no reproductiva.

Analiza entonces qué implica "no ser mujer" desde una selección de comentarios realizados por usuarios de Facebook y por lectores de los portales virtuales de los medios de comunicación Informate Salta, DNI Salta y El Tribuno Salta ${ }^{1}$. Estos comentarios fueron escritos tras la publicación de noticias vinculadas con la marcha del 8 de marzo (8M) del 2018, fecha en la que se celebra el Día Internacional de la Mujer ${ }^{2}$. Las notas refieren a las pintadas realizadas por algunas manifestantes en ese marco: "Las Pintadas del \#8m", "8m\# salteños repudiaron las pintadas que invadieron el centro salteño". En el caso de DNI Salta, los comentarios se extraen de un video que constituye una transmisión en vivo (vía Facebook) de la marcha. En éste se registra el seguimiento insistente de un reportero del medio, Abel Díaz, a un grupo de grafiteras que, en reiteradas ocasiones, le piden que aparte su cámara de ellas. Tras la negativa del cronista y, luego de seguir a un grupo de grafiteras durante el recorrido de casi toda la marcha, una de ellas arroja pintura al lente de su cámara. El episodio fue denunciado mediáticamente por Abel Díaz, quien sostiene haber sido violentado por este grupo de manifestantes. Esta referencia aparecerá en los comentarios que se reponen a continuación. El video fue viralizado y en 24 horas fue visto por al menos 280 mil personas en Salta, fue compartido tres mil veces y recibió al menos dos mil comentarios.

También se retoma parte de los dichos de dos periodistas salteños, Hugo Delgado y Maximiliano Rodríguez, en el programa radial "Ruta 840" (AM

1 Los criterios de selección obedecieron al cruce de las siguientes variables: cantidad de visitas, cantidad de reproducciones, cantidad de comentarios y presencia notoria en redes sociales.

2 El 8 de marzo fue institucionalizado como el Día Internacional de la mujer por decisión de las Naciones Unidas en 1975. 
840), tras el Encuentro Nacional de Mujeres en octubre del 2016.

Nos interesa recuperar parte de estos descargos para pensar las relaciones de poder que con ellos se entraman y las jerarquías sociales que establecen y reproducen, en las cuales se hallan implicadas, solapadas, además del género, otras categorías de la diferencia vinculadas con la orientación sexual, la racialización y la belleza. Los comentarios con los que trabajaremos dan cuenta de la existencia de un marco conceptual que establece un repertorio de valores que estructura y jerarquiza las categorías intersectadas. En esa dirección, el enfoque interseccional considerará la interacción de tales categorías como parte de la estructura organizativa de la sociedad, en la que se legitima ciertas intersecciones entre orientación sexual, género y raza por sobre otras, influyendo y afectando el acceso a la política, el acceso y uso de los espacios, la igualdad y el potencial de cualquier forma de justicia de determinados actores sociales (Hancock, 2007).

La existencia de "múltiples desigualdades", es decir, múltiples dimensiones de estratificación y categorización social, torna indispensable partir de las categorías que les actores sociales construyen y usan en sus prácticas cotidianas, en sus relaciones interpersonales y en las luchas por el poder. Para les $^{3}$ actores, las categorías con las que se diferen-

3 El lenguaje inclusivo constituye una propuesta para que el habla reemplace el uso del universal masculino por vocablos cuyas letras no ignoren la diversidad de respuestas frente al enigma de la relación sexual: vaya como ejemplo el uso del "todes" en lugar del "todos".La incorporación del lenguaje inclusivo en la escritura académica se enmarca dentro de un contexto de lucha y militancia del feminismo en Argentina por la visibilización del sexismo en el lenguaje y el reconocimiento de otres actores en este. Como resultante de este proceso reconocidas instituciones científico- académicas incorporaron estas formas en sus prácticas discursivas. Ver https://www.infobae.com/educacion/2019/08/20/el-len guaje-inclusivo-llega-a-cada-vez-mas-universidades-publicas-y-divide-las-aguas/

https://www.pagina12.com.ar/209773-el-lenguaje-inclusivono-va-en-detrimento-de-la-rigurosidad- cian o identifican con otres se construyen a partir de sus experiencias, en las situaciones concretas en que se encuentran. De allí la importancia de "no son mujeres" y "no soy mujer".

Se piensan y analizan los siguientes comentarios desde una mirada interseccional, en tanto enfoque teórico, empírico y político (Hancock, 2007) a fin de entender la dinámica y composición particular que adquieren las categorías de género, raza y orientación sexual y la forma en que estas categorías son situadas y leídas en los cuerpos y en las prácticas de les grafiteras durante las marchas feministas en la ciudad de Salta. La interseccionalidad es incorporada en el análisis en tanto perspectiva teórica y metodológica que busca dar cuenta de la percepción cruzada o imbricada de las relaciones de poder. El concepto de interseccionalidad ha sido muy útil para superar la conceptualización aritmética de las desigualdades socio raciales como fruto de la convergencia, fusión o adición de distintos criterios de discriminación de las mujeres (Dorlin, 2008). A la par, ha servido para desafiar el modelo hegemónico de "La Mujer" universal, y para comprender las experiencias de las mujeres pobres, lesbianas, trans y racializadas como producto de la intersección dinámica entre el sexo/género, la clase y la raza en contextos de dominación construidos históricamente.

\section{Breves referencias metodológicas}

La opción por abordar la ciudad desde el campo de la comunicación y desde una perspectiva de género supone la coexistencia de múltiples miradas sobre el espacio urbano (Reguillo, 1996). Por ello la metodología de esta propuesta constituye un abordaje cualitativo y transdisciplinario que, de la confrontación de las disciplinas, hace surgir nueva información que las articula entre sí. La visión transdisciplinaria es decididamente abierta, en la medida en que trasciende el campo de las ciencias por medio del diálogo y lo reconcilia 
con el arte, la literatura, la poesía y la experiencia interior (Morin, 1996).

Es preciso dialogar con la "etnografía de la comunicación" para atender a las características de la palabra en circunstancia: las condiciones del espacio, las actividades y reglas de interacción habilitadas o no, las formas de comunicarse en él, la distancias que mantienen entre si los actores, etc. Partimos de la observación directa para analizar la forma en la que los espacios estructuran, determinan y co-construyen los comportamientos, se interroga a los espacios en la reconstrucción de experiencias y situaciones, como si fueran un documento visual donde está impresa toda una realidad e inscrita la vida de todas las personas que los viven.

La propuesta metodológica se inscribe también en una perspectiva de la etnografía que dialoga con la sociología visual y otras disciplinas afines que contribuyen a la reflexión sobre las imágenes y sus usos en ciencias sociales. Como señala Pink (2001), la etnografía se ha caracterizado por una aproximación que presta especial atención a la cultura material y visual de los contextos sociales que investiga, lo cual, en el marco de las perspectivas contemporáneas de la etnografía, supone asumir que el dato visual, al igual que cualquier otro dato, no es una representación objetiva de la realidad sino más bien, una mirada situada sobre ésta.

Bajo dicha premisa es que se construye una serie de constelaciones conceptuales con intención expositiva, en la búsqueda de una genuina yuxtaposición de elementos, como sistema de imágenes e ideas a modo de representación que apela a los fenómenos, sin intentar subsumirlos categorialmente. Ésta es considerada una vía plausible dado el registro empírico sobre el que sostenemos nuestro análisis.

La investigación no sólo construye un registro fotográfico propio de la ciudad de Salta desde los graffitis feministas y transfeministas sino que también, a partir de ese registro, la cartografía para analizar las prácticas de las graffiteras en el espacio y las transformaciones permanentes que éstas introducen. Para ello recupera las imágenes de mapas de la ciudad de Salta de la aplicación de Google Maps, y las interviene y pone en diálogo con las fotografías de las escenas de las graffiteras durante las marchas feministas. Nos identificamos con la cartografía social como metodología participativa y colaborativa de investigación que invita a la reflexión, organización y acción alrededor de un espacio físico y social específico. En este caso la cartografía se delinea no sólo durante el trabajo etnográfico y de registro fotográfico sino también, a partir del relato de las graffiteras entrevistadas. Como metodología de trabajo en campo y como herramienta de investigación, se concibe a la cartografía social como una técnica dialógica (Fals Borda, 1987) que permite proponer, desde una perspectiva transdisciplinaria, preguntas y perspectivas críticas para abordar la construcción de los espacios y las prácticas sociales de las graffiteras.

La investigación también integra el análisis de una selección de discursos mediáticos en torno a las graffiteras y a la práctica de escritura de mensajes anónimos en espacios públicos en el marco de marchas y movilizaciones feministas. Estos abarcan desde noticias periodísticas locales, hasta los comentarios que les lectores de portales y redes sociales de estos medios, realizan a partir de estas noticias desde sus cuentas personales. Creemos que las redes mediáticas e informáticas son orientadoras de la visión y voluntades de poder que pretenden instaurar una matriz total al interior de la cual, un modo de pensar y de vivir queda enmarcado y desde el cual el mundo se expone ante nosotros (Ferrer, 2005). Estos discursos son analizados a contrapelo de los relatos de las graffiteras.

Es esta una reconstrucción analítica de las espacialidades múltiples - que va desde las calles a los espacios virtuales- que componen nuestra escena comunicacional y nos permite dar cuenta de la multiplicidad de voces e imágenes sincrónicas que configuran y delinean los espacios, los cuerpos y las prácticas. 


\section{Taparse la cara, mostrar la piel}

Uno de los elementos constitutivos de toda manifestación política en el espacio público es su dimensión visual. La ocupación del espacio público supone una serie de acciones que les permite a les actores visibilizar sus cuerpos, sus consignas y sus reivindicaciones. En ese sentido, tratar con lo visual entraña interrogarse por lo que se muestra y lo que se oculta o para ser más rigurosos, "por lo que unos actores muestran en determinado momento y ya no posteriormente" (Caggiano, 2012, p. 21). Estas referencias nos permiten pensar en la fuerte dimensión visual de la presencia de las grafiteras en el espacio público durante las marchas y movilizaciones feministas en Salta. Consideramos que ellas componen junto con los grafitis, un vivo y alternativo repertorio visual, una nueva construcción de realidades de la imagen visual del cuerpo, que aparecen para tramitar sentidos de pertenencia y de alteridad y establecen la barrera entre "los otros" y "nosotres", disputando desde ese lugar, la circulación pública de otras imágenes en el paisaje de la ciudad de Salta. La lucha por la visibilidad puede entenderse como una dimensión de la acción colectiva que, partiendo de una situación de invisibilidad o de depreciación simbólica, despliega procedimientos prácticos, técnicos y comunicacionales para manifestarse en una escena pública y generar un reconocimiento de prácticas y orientaciones políticas (Voirol, 2005).

Los procedimientos tácticos y comunicacionales de las grafiteras, generan un nuevo repertorio visual que tiene que ver con recorrer y graffitear la ciudad durante las marchas feministas con el rostro cubierto, una suerte de taparse para ser vistas. Si bien esta acción constituye una estrategia frente a la vigilancia de las cámaras y los policías, también existe allí una elección estética que implica el uso de pasamontañas y pañuelos negros y/o verdes, el uso de prendas oscuras, además de, en algunos casos, la desnudez de sus torsos (Figuras 1 y 2 ).

Nuestro trabajo de campo nos permitió identificar tres grupos bien definidos de personas que pintan la ciudad durante las marchas. El primero

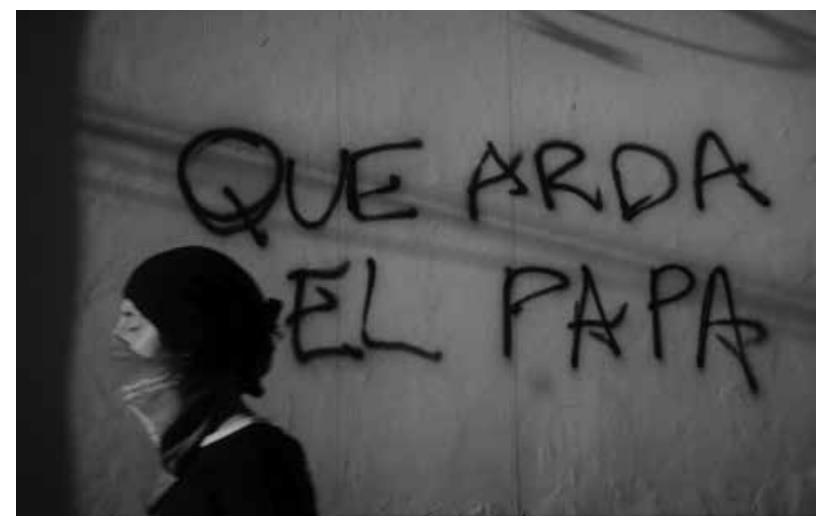

Figura 1. Mujer con pasamontañas en una manifestación. Fuente: elaboración propia.

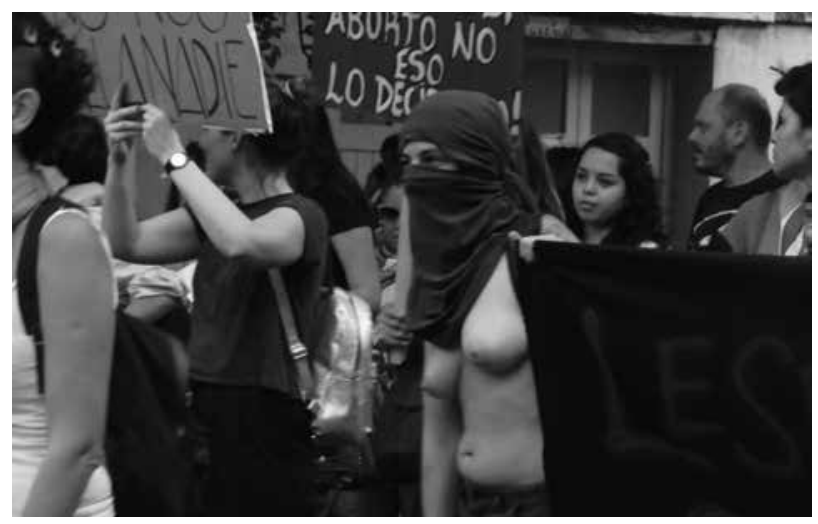

Figura 2. Diversas formas de manifestación. Fuente: elaboración propia.

de ellos, conformado por mujeres, no-mujeres ${ }^{4}$ y varones trans de entre 23 y 28 años, militantes lesbianas y transfeministas. Es este grupo el que presenta además de una estética que les identifica, una fuerte organización previa a cada pintada. Establecen acuerdos no sólo sobre cómo "aparecerán" en las manifestaciones, sino también qué se pintará, dónde, cómo se distribuirán en el espacio y cómo se cuidarán ante situaciones de violencia policial o acoso mediático.

$4 \quad$ No-mujer es una categoría que se deprende de las entrevistas realizadas a las grafiteras, en dichos relatos se usa para dar cuenta de una configuración identitaria que resiste y se revela frente a los mandatos patriarcales en torno a la "belleza", los "buenos modales", la delicadeza, las disposiciones maternales, la heterosexualidad y los espacios asignados socialmente a las mujeres, como el espacio doméstico. 
Este grupo no sólo se organiza para graffitear en el marco de marchas, también lo hace por fuera de estas fechas. Escrachan-señalan espacios vinculados de alguna manera con abusadores, violadores, o personas que hayan sido expuestas por sus opiniones en contra del feminismo, la legalización del aborto, o comentarios lesbofóbicos. Les integrantes sostienen que se busca fortalecer la organización de estas pintadas más allá de las marchas.

También empezar a pensarlo como algo que no tenga que ver con la marcha en sí, o con una fecha, con la agenda que imponen en la sociedad, sino que sea una agenda hecha por las mujeres, empezar a hacer esas actividades también en otros...para empezar a molestar. No solamente cuando se acerca una fecha, o algo que ya se sabe porque muchas veces hasta se espera, sino que...de repente un día te levantes y tengas todo pintado y no tenga que ver con un ocho de marzo, con un 3 de junio, con un 17 de noviembre (P.R. en situación de entrevista)

Un segundo grupo de grafiteras se encuentra conformado por mujeres más jóvenes de entre 18 y 23 años de edad (con menos integrantes), que actúan de manera más improvisada y no se identifican fácilmente ni por un color, ni por una estética particular. A propósito, muchas de ellas fueron alertadas por algunas militantes para que cubrieran sus rostros como medida de resguardo luego de que el diario El Tribuno publicara la siguiente fotografía, denunciada posteriormente y eliminada de la página del medio, por no contar con la autorización de las personas que aparecen en la imagen y por el acoso y situaciones de violencia a la que éstas fueron expuestas (Figura 3).

Finalmente, encontramos un tercer grupo, conformado por mujeres que acuerdan en pareja salir a pintar durante las marchas. En estos casos, la práctica resulta más espontánea y no busca replicarse en el tiempo: "No, yo creo que fue sólo ese momento, porque lo necesitaba. No creo que vuelva a salir a pintar de nuevo" (Lala, en situación de entrevista, 20 de mayo del 2018).
四 (1) เล ละ $1177 \%$ ด $18: 48$

$\times$ Las pintadas de la...

COMPARTIR :

a www.eltribuno.com

랄 El Tribuno

editicios publicos ni privados. Entre los

mensajes que más se repitieron hubo

consignas a favor del aborto y en contra

de la iglesia.

- Una multitud le dijo basta a la amenaza diaria del femicidio

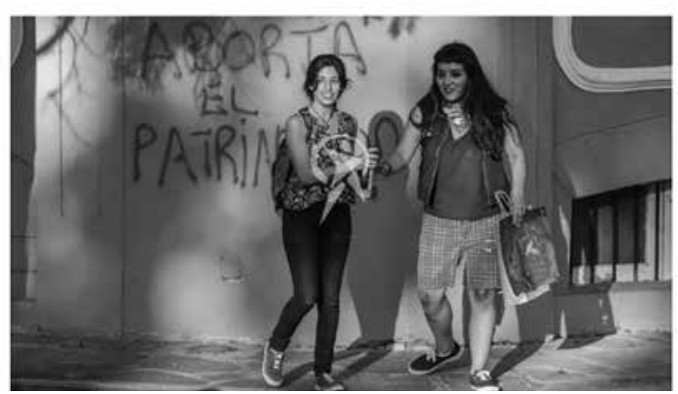

Figura 3. Imagen de dos mujeres después de pintar en la Legislatura: Foto: Pablo Yapura (El Tribuno).

A pesar de que los grupos que graffitean las paredes del centro salteño durante las marchas feministas son heterogéneos en composición, el foco de esta práctica suele ponerse generalmente sobre el primero de ellos. Parte de la crónica relatada por el periodista de DNI Salta las describe de la siguiente manera: "Estado asesino es lo que pintan en las paredes de los edificios públicos, estas chicas que van, como las viste vos, con gran parte del rostro cubierto y con los senos totalmente al aire, descubierto, sin remera, como lo viste." (Abel Díaz, transmisión en vivo vía Facebook, 8 de marzo del 2018).

El diario El Tribuno de Salta, acompaña la nota titulada "Las pintadas del 8M", con las imágenes que veremos a continuación, donde aparecen personas, vestidas completamente de negro y con 
sus rostros tapados. En la primera imagen una de las personas fotografiadas pinta la pared de la Legislatura mientras que otra, con el torso desnudo y pixelado en la edición, acompaña la acción. En la segunda imagen aparecen tres militantes, también con sus rostros cubiertos pintando las paredes del Banco Nación.

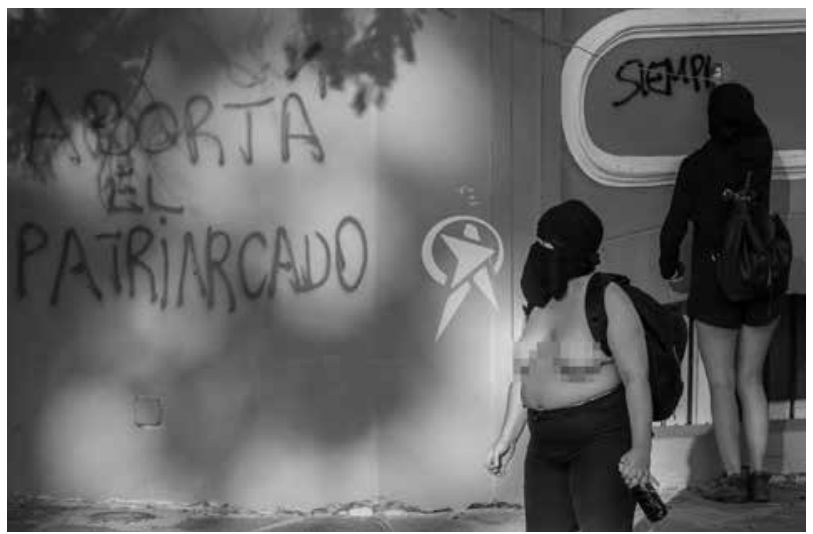

Figura 4. Realización de grafitis en las paredes de la Legislatura. Fuente: elaboración propia.

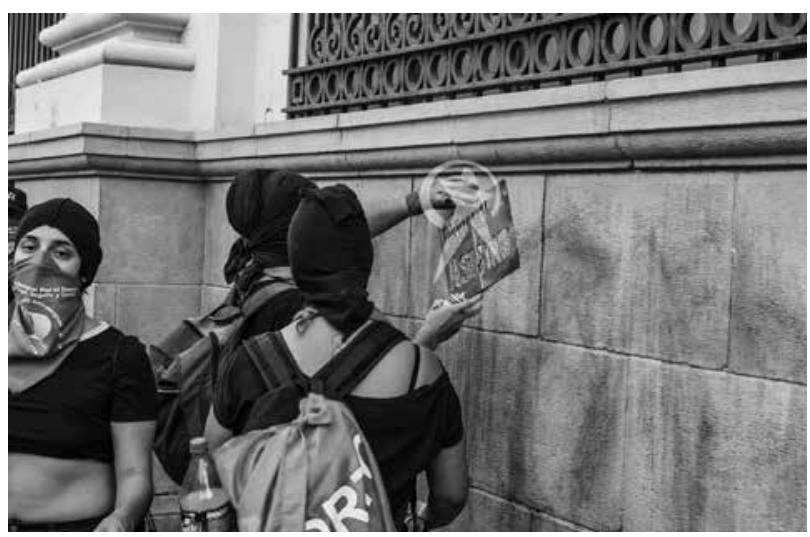

Figura 5. Realización de grafitis en las paredes del Banco Nación. Fuente: elaboración propia.

La aparición de personas con el rostro tapado o cubierto en escenarios públicos y en la prensa, por lo general suele ser asociado con operativos policiales en los que la cara de los sospechosos es cubierta porque la ley asume su inocencia hasta probar lo contrario, de esta forma se resguarda su intimidad. Pero también, al menos durante la década de los 90 los medios masivos de comuni- cación de Argentina, adoptaron la modalidad de ocultar el rostro de las personas que aparecían en las imágenes de notas referidas o vinculadas con inmigrantes. Caggiano (2012) sostendrá que mediante estos mecanismos de ocultamiento del rostro (pixelar la imagen, tomar la fotografía sin que los sujetos miren a cámara), algo del carácter policial que tienen las imágenes de personas con el rostro tapado, se volvió parte de la visualización general de las/os inmigrantes. Así todas estas fotografías, aún las de contextos laborales de los inmigrantes, contribuyeron a la construcción visual de una "infralegalidad de los cuerpos" (p. 30).

¿Qué sucede cuando el ocultamiento del rostro constituye una acción voluntaria de quienes graffitean el espacio durante las marchas feministas? ¿Esta infralegalidad de la que nos habla Caggiano se transfiere también a ellas?

$\mathrm{Al}$ vedar sus rostros las grafiteras generan un marco de desconcierto ya que privan al resto de les actores sociales, de la posibilidad de reconocerles en su identidad social. Con identidad social me referiré a aquella identidad reconocida a partir de grandes categorías sociales a las que se pertenece, puede pertenecer y verse que pertenece un individuo. No puede inferirse de ellas, por ejemplo, grupo etario o clase social (Goffman, 1971, p.195). Es a partir de esta identidad social, que opera como ordenadora de las interacciones cotidianas en el espacio público, que se estructura un trato entre los individuos que se conocen exclusivamente a través de ellas, esto hace posible que el anonimato de las interacciones cotidianas en el espacio público no se exprese como alarmante ni amenazante.

De allí que las grafiteras compongan una imagen que, como veremos, se encuentra fuertemente criminalizada, y esta criminalización implica al mismo tiempo un proceso de masculinización que cuestiona el carácter de "mujeres" de quienes transitan la marcha pintando mensajes en las paredes. Como veremos en seguida, junto a este señalamiento de las grafiteras como delincuentes, aparecerá también un efecto racializador que 
pondrá en entredicho las capacidades de estas personas para ejercer libremente sus derechos como ciudadanas pues, la alusión racial evocará una serie de falencias vinculadas a la barbarie y la irracionalidad que apuntan a diferencias cívicas (Caggiano, 2012).

Sobre los rostros cubiertos que zigzaguean el espacio dejando trazos con pintura recae un llamado de atención o interpelación de un poder, una fuerza que al mismo tiempo que le demanda referencias de esa identidad social categorizante, le ofrece a les grafiteras una suerte de reconocimiento (Butler, 2002). Mediante esta reprimenda que recae sobre las grafiteras que ocultan su rostro y exhiben su pecho, no sólo reciben reconocimiento, sino que además alcanzan cierto orden de existencia social, al ser transferidas de una región exterior de indiferencia, al terreno discursivo o social del sujeto. Cómo son esos discursos y qué tipo de sujetos recrean.

\section{"Green is the new black": Criminalización y racialización de les grafiteras}

La mayoría de los comentarios analizados consideran que taparse la cara -lejos de ser visto como una herramienta de visibilización anónima-, es considerado producto de la vergüenza que le generaría a les grafiteras, pintar y "dañar" las paredes de la ciudad. Los comentarios enfatizan en que pintar las paredes constituye un "daño", y a partir de éste se construye la idea de ilegalidad, criminalización, vandalismo, violencia.

Diego Fe - 19:04 Jajajajaaa.....le taparse la jeta a la boluda esal!I!I Mandala a laburar a la cara de piqueterall!! Se me hace q ni ella sabía por q estaba marchando....jajaja

Me gusta - Responder - 32 sem

Figura 6. Comentario publicado en un diario local. Fuente: D.N.I Salta (2018).
Como bien mencionábamos, existe en una cultura visual, un sentido común visual (Caggiano, 2012) que liga el rostro cubierto, tapado, vedado, con los hechos delictivos, el crimen, la violencia y, por otra parte, personifica estos elementos bajo categorías racializantes tales como "negros", "negros de mierda", "yutos", etc.

El uso de los apelativos "negras", "yutas", "patoteras", e incluso "piquetera" aparece en los comentarios asignando un rasgo racial no necesariamente visible. Constituye más bien una marca racial en lo que es fundamentalmente una identidad de clase y género antes que una identidad propiamente étnica. La identificación actual "negra/as" no traza en estos comentarios ninguna línea entre dos comunidades bien diferenciadas, sino que se utiliza como un marcador racial para definir una posición de clase, de género y particularmente de orientación sexual. Si bien tanto la categoría de género como la de raza suelen estar ancladas a referencias biologisistas, y se ha buscado a lo largo de la historia apoyar estos dos criterios de clasificación social en concepciones pretendidamente "naturales", "el empleo de estas categorías depende siempre de la organización, de las creencias y las imposiciones sociales extensivas" (Tilly, 2000, p. 21).

En Argentina, estas creencias, hicieron a la superposición de categorías intersectadas a partir de las cuales, por ejemplo, ser joven, varón, de tés morena y cabello oscuro, implicó ser sospechoso o culpable y en algunos casos, foráneo, extranjero (Caggiano, 2012). Esta construcción de realidades visuales, establece el repertorio o parte del repertorio desde el que se ve y lee los cuerpos de las grafiteras, que no solo serán racializados como efecto de la criminalización de sus prácticas, sino también masculinizados, en tanto el ejercicio de la violencia que se les atribuye, es legítimo para las masculinidades hegemónicas. El siguiente comentario parece concentrar gran parte de las categorías mencionadas: “(...) se portan peor que los vagos, aparte las que vi yo no eran de Salta, parecían de afuera, marimachos marihuaneras". 
Esta idea de que "vienen de afuera", si bien no es tan recurrente en los comentarios que seleccionamos, si es una idea muy presente en otros circuitos comunicacionales. Durante el trabajo de campo realizado en el 2018, luego de la marcha del 8 de marzo, hablamos con distintas personas - seleccionadas al azar- que circulaban por el microcentro, para indagar su opinión sobre las pintadas feministas. Una persona que tiene un pequeño puesto de mazas dulces sobre la calle Mitre, una de las zonas que hierve de grafitis feministas, nos aseguró que quienes pintaron los mensajes -aún frescos hasta entonces- "bajaron de un colectivo enorme, no eran de acá" (Vendedora de la calle Mitre, 11 de marzo de 2018). También una de las diputadas nacionales que se opone bajo argumentos morales y religiosos a la legalización de aborto, entiende que el feminismo y la demanda de dicha ley no son representativos de Salta, de la "salteñidad". Sus palabras textuales fueron

Hay que entender que la Argentina no es sólo Buenos Aires, que es amplia y diversa. Lo que pueda aparecer en los medios o en las calles de Buenos Aires no refleja a todo el país y menos lo que piensan los salteños (...) en Buenos Aires se vive un microclima y al vivir eso uno cree que esa parte de la sociedad representa a todos. Claramente no es así, Salta es diferente (Diputada Nacional Fiore, Diario Cuarto 29 de junio del 2018).

En términos de Caggiano (2012) esta operación constituye una "extranjerización de la delincuencia” que supone grafitear las paredes. En necesario depositar esa "violencia" lejos de las murallas imaginarias que conforma la "salta colonial" de buenas costumbres.

Desde los comentarios también se criminaliza el reclamo de los feminismos por la legalización del aborto. El uso del pañuelo verde (símbolo de la campaña por la legalización del aborto) les vale a las grafiteras ser llamadas además asesinas y violentas. Aun cuando el pañuelo verde es usado por la mayoría de las personas que asisten a las marchas y movilizaciones feministas, los medios masivos de comunicación, se centraron hasta hace algunos años, en visibilizar a les grafiteras como "la cara visible" del feminismo y de la demanda por la legalización del aborto.

\section{"Esas no son mujeres"}

Las primeras marchas, de hecho una muy grande que hubo en Jujuy en su momento, también donde fueron destrozados todos los monumentos históricos con pintadas, todas agresivas contra los hombres. Yo creo que por ahí la mujer... cotidiana, por ponerle un adjetivo, no va con el tubo de aerosol a pintar "curas esto..." o "funcionarios lo otro", va y marcha (Rodríguez y Delgado en el programa "Ruta 840", octubre del 2016).

Durante la marcha del $8 \mathrm{~m}$ de 2018, Abel Díaz cronista de DNI Salta, mantiene un breve intercambio con una de las grafiteras, ella le pide que se aleje, que registre el resto de la marcha y él contesta: "yo quiero hablar con las mujeres en realidad". Este es un elemento que se repite en la mayoría de los comentarios seleccionados: "ellas no son mujeres, son lesbianas". Incluso cuando muchas lesbianas no adscriban a la categoría de "mujer" ni a la identidad en términos binarios, la masculinización de ellas aparece como una forma de violentarlas en su identidad. Al igual que la experiencia que describe y analiza Canessa (2008) en Copabaya-Bolivia en relación a los varones que entran al servicio militar en Bolivia y que son vestidos como mujeres campesinas cuando no pueden aguantar los rigores de la vida militar, las grafiteras aquí son masculinizadas al correrse de los roles establecidos socialmente para las mujeres o aquellas personas leídas socialmente como tales. Nos interesa señalar este caso porque nos permite pensar en la feminización y la masculinización de los cuerpos como una forma de castigo, burla, disfraz.

El espacio público fuertemente asociado al espacio público político, localiza la actividad política en las calles, y las mujeres y no mujeres no se encuentran ni en uno ni en otro espacio en los repertorios de imágenes hegemónicos. Por ello la apropiación 
de las calles, sus paredes y sus plazas, pone de manifiesto que el espacio público en tanto espacio político, constituye un frente de batalla prioritario en las disputas visuales de género (Caggiano, 2012). En este sentido, es el espacio lugar en el que se materializan e intersectan una serie de desigualdades y jerarquías sociales que tienen que ver con ser mujer, con no ser mujer, pero ser vista y leída socialmente como tal, con ser lesbiana, con ser feminista, por cruzar y transgredir permanentemente la supuesta frontera entre espacios privados y espacios públicos políticos.

Peter Wade (2008) dirá que allí, donde existe una jerarquía social, esa jerarquía tiene dimensiones racializadas y una técnica común en la dominación, es el control sobre la sexualidad y el sexo: sea por medio del abuso sexual (la violación) sea por el control de las relaciones sexuales y el comportamiento sexual, sea por medio de la cosificación y fetichización del subalterno en términos sexuales, ya sea como objeto de deseo u objeto de repugnancia.

\section{Noelia Villarreal · 33:17 Mujeres??? Asco} dan!!!

Figura 7. Comentario publicado en un diario local. Fuente: D.N.I Salta (2018).

\section{Soldado Bajo Bandera thace 8 meses}

EI Dia era de LA MUJER, no de las Tortilleras, Marimachos, Lesbianas, o como se las quiera denominar. Subversivas violentas. ¿Y la "justicia"?, bueno, la "usticia" no tomó ninguna medida porque tambièn ella es Subversiva, por eso está de parte de la Guernlla de los delincuentes, de las Tortas, es decir a favor de todo lo que signifioue subvertir (invertir) los Valores Naturales para Destruir EL ORDEN NATURAL. $4 \wedge \vee$. Compartís

Figura 8. Comentario publicado en un diario local. Fuente: Diario el tribuno (2018).

Encontramos una gran cantidad de comentarios similares, la mayoría de éstos dan cuenta de un doble movimiento, por un lado, se asume que las grafiteras son lesbianas independientemente de que esta categorización cuente con datos específicos y, por otro lado, se las masculiniza. Esta masculinización al mismo tiempo supone una voluntad frustrada por parte de ellas que, "quieren ser hombres, pero nunca podrán serlo".
Cesar Mauricio Navarro Nos odian porque no nacieron con un pito jaja

Me gusta - Responder - $3 \mathrm{~h}$

Figura 9. Comentario publicado en diario local. Fuente: D.N.I Salta (2018).

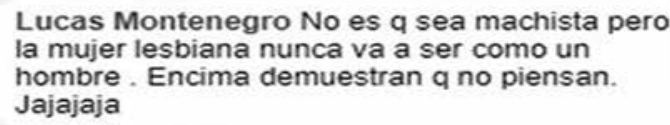

Figura 10. Comentario publicado en un diario local. Fuente: Diario el tribuno (2018).

Los comentarios construyen la idea de que una lesbiana es una mujer que, o tuvo una mala experiencia con un hombre o aún no ha encontrado "al indicado". Estos "diagnósticos" suponen que "ser lesbiana" es resultado de "una falla de la maquinaria del sexo heterosexual, con lo cual continúa instalando la heterosexualidad como causa del deseo lesbiano que es siempre y solamente una máscara (Butler, 2002). La intersección mujer- heterosexual aparece en la jerarquización social por sobre la de no-mujer-lesbiana. Desde los comentarios se construye la idea de que la mujer sólo es heterosexual, delicada, cuidadosa, dócil.

En esa dirección, la imagen de algunas grafiteras configura el no efecto o no resultado de la corporización de estas normas (delicadeza, docilidad, amabilidad, etc.) ni de categorías hegemónicas (mujer-hombre), por el contrario, es la figura de un cuerpo que entorpece ser ordenado según ciertos esquemas, es el no ideal morfológico que posibilita la lectura de sí, al mismo tiempo en que la dificulta: "son mujeres" pero no se ven ni se comportan como tal, parecen hombres, pero no lo son, son lesbianas, son negras, son violentas, son vistas a pesar de llevar el rostro cubierto, por tanto "la posibilidad de lectura significa aquí, degradar a alguien exponer lo que no funciona en el nivel de la apariencia, insultar o ridiculizar" (Butler, 2002, p. 190). Esta situación a la que son expuestas muchas personas con identidades disidentes, no binaries, lesbianas y trans, es narrada en el poema de la tucumana Macarena Diosque. En éste la mirada del otro no sólo construye un relato de ese cuerpo visto, una lectura, sino también, es una mirada que exige 
la "normalización" de ese cuerpo visto-leído a un género, a unas prácticas, a unas categorías quietas, a fin de no inquietar las miradas que sólo pueden ordenar mujeres y varones:

Camino por la calle

y una señora me mira fijo

Fijo enojada fijo

a la altura del pecho

Un puto

me desea

el culo

pero sólo

porque piensa

que tengo

una pija

Ahí adelante

en el medio.

En la fila del Rapipago

una nena pregunta

mientras me señala

Por qué ese chico

usa esos aritos

Y le contestan

los varones

también pueden usar

aritos.

Voy de noche

por la Avellaneda

De banda sonora original

me suena el comentario

de alguna que me dijo

Tranca

vos vas segura

porque das varón

La pateo

sometiéndome

al azar

de la mirada ajena

Quien te dice

confundo a un chongo

y me pega

por maricón

(...)

Pienso yo ahora que

una bomba a las que consiguen ver- me a

quienes me desean mujer a

las que rechazan mi masculino

Una bomba a

tu cissexismo

que intenta reforzar el internalizado mío

y por ahí me quiere obligar

a volverme más amena

a tu vista

a tus gustos

a tus maneras

Menos puto

más activa

más pasiva

menos tortillera empedernida

Elegí un casillero

(Diosque, 2019)

Por otra parte, los escritores de los comentarios seleccionados cuestionan incluso, la capacidad de las grafiteras, negras y lesbianas de desarrollar una erótica propia pues, se las considera no atractivas en términos físicos y se construye algo muy similar a lo que Canessa identifica como una erótica del poder: las lesbianas no son deseadas por sus condiciones físicas, pero necesitan vincularse sexualmente con un hombre para alivianar esa frustración.

La violación física aparece en los comentarios como una forma de violencia dirigida sólo a mujeres heterosexuales y físicamente atractivas, por lo que las lesbianas, en sus condiciones físicas estéticas, no son destinatarias "ideales" de este tipo de violencia. Estas operaciones no sólo producen la invisibilización de la violación como una forma de violencia física que padecen las lesbianas, que en la mayoría de los casos adquiere un carácter "correctivo" de la orientación sexual, sino que también deslegitiman y banalizan la denuncia que estas identidades pueden realizar frente a estas situaciones.

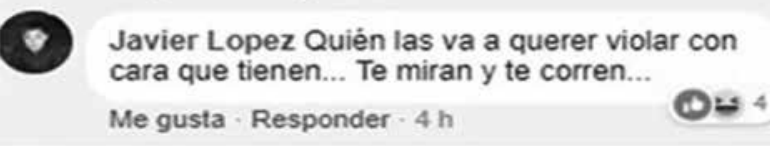

Figura 11. Comentario publicado en un diario local. Fuente: D.N.I Salta (2018). 
En este punto, resulta interesante pensar y dialogar con los estudios sobre violaciones realizados por Rita Segato (2010). La antropóloga sostiene que la violación se percibe como un acto disciplinador y vengador contra de una mujer genéricamente abordada. Al destacar el carácter genérico de la mujer abordada indica que se trata de cualquier mujer y que su sujeción resulta necesaria para la economía simbólica del violador como índice de que el equilibrio del orden de género se mantiene intacto o se ha restablecido. La mujer genérica es una mujer sujeta al papel femenino, posee un itinerario fijo en la estructura gramatical de la violación. Esto no quiere decir que las lesbianas queden exentas de una violación, en la mayoría de los casos la violación a lesbianas es leído como una forma correctiva, reforzando de esa manera el carácter dominante de la erótica del poder arriba mencionada.

Todo el relato y el análisis apunta a señalar que la ciudad de Salta no sólo se configura como un espacio en donde las mujeres aparecen subordinas y donde las demandas políticas de las mismas no son codificadas como tales, sino que también es un espacio fuertemente heterosexuado, "donde los colectivos gays sufren acoso y agresiones en los espacios públicos cuando se manifiestan abiertamente" (Valentine, 1993, p. 293).

La heterosexualidad es aun en la actualidad, la sexualidad dominante en nuestra sociedad. Ésta no sólo se define por las prácticas sexuales en el espacio privado, sino, que es un proceso de relaciones de poder que opera en la mayoría de los entornos cotidianos, en las calles, en los espacios virtuales. Las formas en las que la hegemonía heterosexual se reproduce, se expresa como vimos, en el espacio a través de la discriminación y la violencia (Valentine, 1993).

\section{"Yo no soy mujer"}

Escribo desde la fealdad y para las viejas, las feas, las camioneras, las frígidas, las mal folladas, las infollables, las histéricas, las taradas, todas las excluidas del gran mercado de la buena chica $[. .$.$] Yo soy ese tipo de mujer con la que$ no se casan, con la que no tienen hijos, siempre excesiva, demasiado agresiva, demasiado ruidosa, demasiado gorda, demasiado brutal, demasiado hirsuta, demasiado viril, me dicen. Así que escribo aquí como mujer incapaz de llamar la atención masculina, de satisfacer el deseo masculino y de contentarme con un lugar en las sombras (Despentes, 2018, p. 13).

La identidad de no-mujer a la que refieren algunas de las grafitieras entrevistadas, configura un nuevo sujeto que escapa al binomio hombre- mujer. Esta identidad supone otras posibilidades de la palabraacción en la ciudad, al menos, durante las marchas feministas.

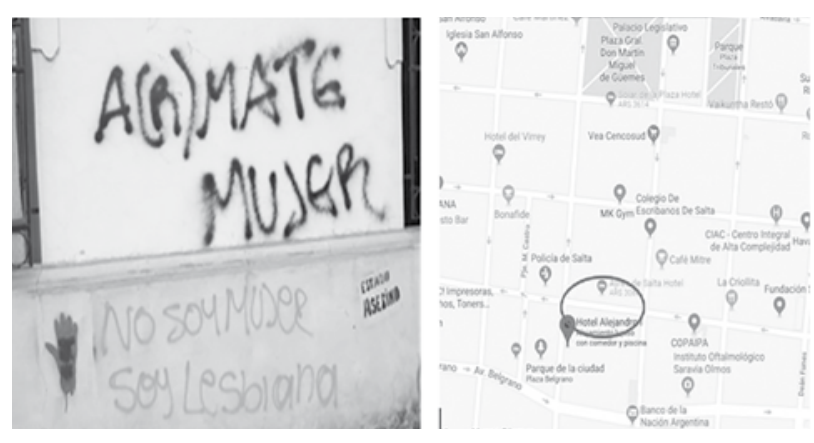

Figura 12. Grafiti y su situación geográfica. Fuente: elaboración propia.

"Ármate mujer", "No soy mujer, soy lesbiana" no sólo constituye un mensaje que nos permite pensar en la figura de la no-mujer, al mismo tiempo, muestra un dialogo interno en el feminismo entre dos sujetos diferentes. En esa dirección, este mensaje señala la tensión entre un feminismo que reduce el "sujeto político" a las mujeres y otro sector, que abre la posibilidad de pensar el feminismo más allá de las mujeres.
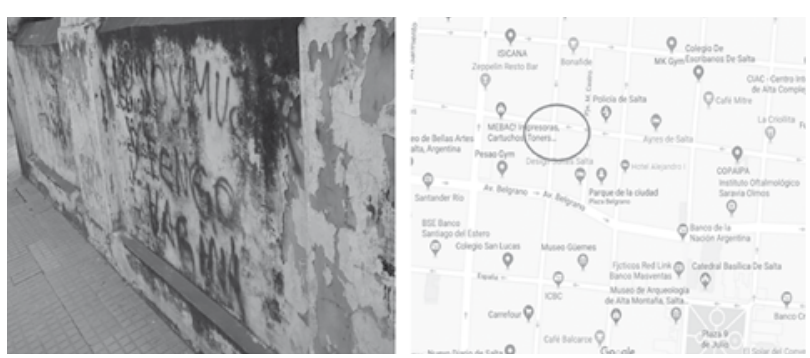

Figura 13. Grafiti y su situación geográfica. Fuente: elaboración propia. 
Si hablamos sobre las tensiones internas que los grafitis feministas y transfeministas nos permiten leer dentro del movimiento, "No soy mujer y tengo vagina" dialoga y responde a las ideas biologisistas presentes en ciertos sectores del feminismo en Salta, que entienden el género como la construcción sociocultural del sexo, y al hacerlo, reproducen el binarismo "hombre- mujer", cultura-naturaleza que opera como una producción disciplinaria del género que lo estabiliza falsamente para garantizar los intereses de la construcción y la regulación heterosexual en el ámbito reproductivo. El feminismo de "mujeres" no logra dar cuenta de las discontinuidades de género que están presentes en el contexto heterosexual, bisexual, gay y lésbico, los grafitis feministas y transfeministas, dan cuenta de estas discontinuidades.

Creo que cuando dicen "esas no son mujeres", la idea es violentar la identidad porque ellos piensan, en mi caso, piensan que soy mujer, nacida mujer y que me están corriendo de un lugar al cual yo quiero pertenecer. Cuando dicen "esas no son mujeres" para mi es hermoso. ¡Alguien me leyó como yo quería que me lean! (M.D., en situación de entrevista, 7 de mayo del 2018)

Existe una reapropiación positiva ante esta forma de violentar la identidad que muchas grafiteras enfrentan, una suerte de conversión del estigma en emblema. Para algunas "no ser mujer" constituye una salida frente a los mandatos impuestos.

S.G, otra de las grafiteras entrevistadas, retoma un comentario escrito por un lector de un diario digital de Salta que, según ella, define lo que es ser mujer y explica por qué entonces, no adhiere a esta categoría.

Eh, mira, quiero leerte un comentario que vi hoy y digo, esta persona, describe perfectamente lo que significa ser mujer (saca el celular y comienza a leer). Porque dice "Manga de yutas las feministas, éstas hacen daño, ser mujer, es quedarte en tu casa, haciendo cosas y cuidando a tus hijos. Estas son mujeres que mal educan a sus hijos por eso los chicos están tan mal y se drogan y se suicidan". Entonces, pienso que la construcción del imaginario social de lo que es ser mujer, es tener un marido, ser una persona que busca todo el tiempo el respeto, agradarle a los demás, tener paciencia, ser comprensiva, educar al otro... Son todas esas cosas las que me hacen renunciar al concepto de mujer por más que yo sea socialmente leída como mujer...porque me visto como mujer, cumplo muchas cosas que parecen de mujer. Para mí fue muy necesario romper con esa idea de ser mujer y reivindicar más al transfeminismo porque no quiero responder a esos estereotipos que me exigen... Porque cuando salen las chicas con la cara tapada y en tetas a pintar calles, lo primero que dice la gente es "estas no son mujeres" y si, no somos mujeres porque no estamos haciendo lo que la sociedad quiere que hagan las mujeres. (S. Gil, en situación de entrevista, 11 de abril del 2018).

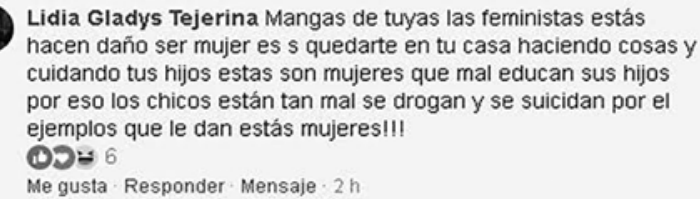

Lidia Gladys Tejerina Mangas de tuyas las feministas estás hacen daño ser mujer es s quedarte en tu casa haciendo cosas y cuidando tus hijos estas son mujeres que mal educan sus hijos por eso los chicos están tan mal se drogan y se suicidan por el ejemplos que le dan estás mujeres!!! (1) $=6$

Me gusta Responder Mensaje $\cdot 2 \mathrm{~h}$

Figura 14. Comentario publicado en un diario local. Fuente: D.N.I Salta (2018).

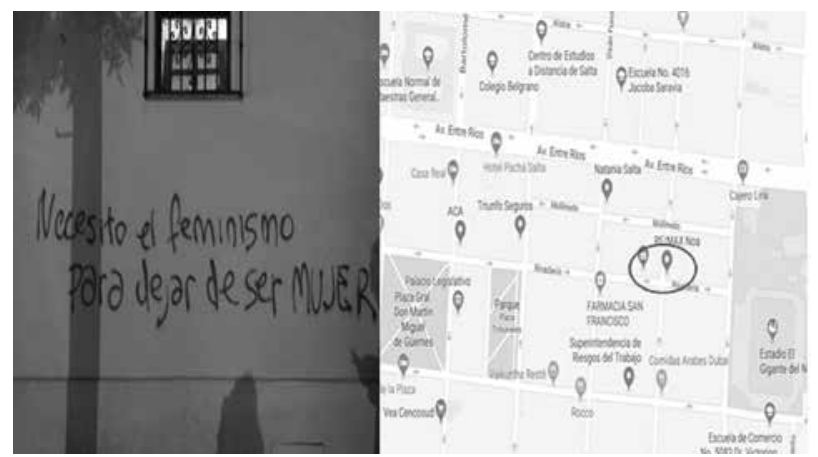

Figura 15. Grafiti y su situación geográfica. Fuente: elaboración propia.

Un nuevo sujeto se desplaza por la ciudad. Es leído como mujer sin serlo y es sancionado como no-mujer por no hacer, verse, ni escribirdecir aquello que se espera. Es un sujeto que se reinventa, se elabora a sí mismo en tanto forma reflexiva con el presente y logra hacer de su cuerpo, su comportamiento, sus sentimientos y pasiones, una herramienta que cuestiona el orden simbólico 
“Grafiteras, negras y lesbianas": la escritura de grafitis feministas en la ciudad de Salta, Argentina

de la ciudad y esparce nuevas sensibilidades allí donde no estaba previsto.

La mujer que recurre a esta práctica está poniendo en debate la femineidad, sus roles... porque yo veo grafitis todo el tiempo. Pero ¿por qué molestan tanto los grafitis feministas? Hay dos razones, porque escriben las mujeres $y$ esto choca mucho con la femineidad - que yo la defino como una cárcel-, es como que tenés que hacer sí o sí ciertas cosas. ¿Por qué somos tan criticadas las feministas que tomamos estas prácticas? Nosotras realmente tenemos un mensaje, tenemos una lucha, tenemos un montón de historia, el feminismo está lleno de historia, cada feminista tiene su historia y toda esa carga emocional, toda esa energía que te mueve, nadie lo puede ver. ¿Por qué? Porque está primero el sistema, lo que te dice, el mandato, la repartición de roles, "vos sos mujer, vos no podes hacer eso. Está mal, el hombre sí puede (Flor, en situación de entrevista el 10 de mayo del 2018).

La categoría no- mujer, agrupa aquí, tanto a las sexualidades disidentes de algunas grafiteras, como también a las identidad heterosexual de otras. Es parte de una identidad que se asume de manera estratégica según el contexto y los objetivos establecidos. Una identidad que, como sostiene Judith Butler (2002) no se constituye a partir de la materialidad del sexo y que por ello permite indagar otras premisas que operan como irreductibles políticos. La práctica feminista o tránsfeminista aquí, cuestiona la necesidad de recurrir a la materialidad del sexo para fundamentarse a sí misma. En esta dirección la cuestión no estriba en establecer si es necesario o no hacer mención a esta materialidad ni tampoco si debe hablarse o no de mujeres. Se hablará y por razones feministas debe hablarse de "mujer", pero esta categoría ya no se reifican como referente único y presenta la posibilidad de apertura para significar aquello que no puede definirse de antemano. Por ello, y como menciona Ayelén - otras de las grafiteras entrevistadas- el término es usado de forma estratégica y como señala Butler, es sometido a crítica para cuestionar las operaciones excluyentes y las relaciones de poder diferenciales que construyen y delimitan las invocaciones feministas del término mujer.

Yo estoy en esa de ir desarmando los términos "feminista", "mujer". Utilizamos la palabra mujer de forma estratégica, en ciertos contextos por ahí está bueno utilizarla. Yo no me considero mujer pero en algunos momentos para referirte en las luchas, en los movimientos, los colectivos...uso la palabra mujer o...cómo expresar estas ideas ante personas que tal vez no entienden otros conceptos o no manejan otro lenguaje (Aye, en situación de entrevista, 15 de mayo del 2018).

\section{Conclusiones preliminares}

Las grafiteras, negras y lesbianas, los rostros cubiertos son elementos que se reúnen en este artículo para dar cuenta de una nueva presencia en el espacio urbano que, en su condición anónima, propone un nuevo reparto y distribución de las palabras, las imágenes y los cuerpos en la ciudad.

Estos nuevos "otros" que se desplazan durante las marchas feministas escribiendo la ciudad, no sólo logran cuestionar y revertir momentáneamente la distribución hegemónica de lo visible y lo decible en la ciudad de Salta, también problematizan y diversifican las identidades que componen del movimiento feminista. En ese sentido, lo que se revisa y cuestiona de manera directa desde el contenido de los grafitis, la disposición y la coreografía de los cuerpos de las grafiteras durante las marchas, es la categoría de mujer. Las grafiteras hacen un uso estratégico de esta categoría y la someten a una crítica que problematiza las operaciones excluyentes y las relaciones de poder diferenciales que se construyen y delimitan tras el término "mujer" o "mujeres". Esas operaciones de poder y exclusión se manifiestan, como expusimos bajo la frase "no son mujeres".

En esa dirección fue indispensable sumar al análisis de las desigualdades de género manifiestas en la ciudad, un enfoque interseccional capaz de agudizar la reflexión. La orientación sexual entonces, se introduce en el trabajo como una dimensión que 
profundiza la disparidad en el acceso y el uso de los espacios de la ciudad, al mismo tiempo que supone una operación de racialización, heteronormativización, y criminalización que recae sobre las grafiteras. Las referencias de índole racial remiten fundamentalmente, a una identidad de clase y género antes que una identidad propiamente étnica. La identificación de las grafiteras como "negra/as" no traza en los comentarios analizados ninguna línea entre dos comunidades bien diferenciadas, sino que se utiliza como un marcador racial para definir una posición de clase, de género y particularmente de orientación sexual. En ese sentido se puso de manifiesto que el espacio de la ciudad, además de ser un espacio masculinizado, también es un lugar normado en función de una heterosexualidad hegemónica.

\section{Referencias bibliográficas}

Butler, J. (2002). Cuerpos que importan. Buenos Aires: Paidós Editorial.

Caggiano, S. (2012). El sentido común visual. Disputas en torno a género, "raza" y clase en imágenes de circulación pública (pp. 151-195; 257-288). Buenos Aires: Miño y Dávila editores.

Canessa, A. (2008). El sexo y el ciudadano: Barbies y reinas de belleza en la era de Evo Morales. En: Wade, P., Urrea Giraldo, F. y Viveros Vigoya, M. (Eds.). Raza, etnicidad y sexualidades. Ciudadanía y multiculturalismo en América Latina (pp. 69-105). Bogotá: Universidad Nacional de Colombia, Centro de Estudios Sociales,

Despentes, V. (2018). Teoría de King Kong. Madrid: Penguin Random House.

Dorlin, E. (2008). Introduction: La Révolution du féminisme noir!. En: Carby, H.,Guy-Sheftall, H., Harris, L. A., Collins, P. H., Hooks, B., Lorde, A. et al. (Eds.). Black feminism: anthologie du féminisme africain-américain, 1975-2000 (pp. 9-42). París: L'Harmattan,.

Fals Borda, O. (1987). "Ciencia propia y colonialismo intelectual. Bogotá: Nuevos rumbos.
Ferrer, C. (2005) "Mal de ojo. El drama de la mirada. Buenos Aires", Colihue

Goffman, E. (1979). Relaciones en público. Microestudios del orden público. Madrid: Editorial Alianza.

Hancock, A. M. (2007). When Multiplication Doesn't Equal Quick Addition: Examining Intersectionality as a Research Paradigm. Perspectives on Politics, Vol. 5/No. 1, pp. 63-79.

Hill, R. J. (2002). In the shadows of the arch: Safety and acceptance of lesbian, gay, bisexual, transgendered and Queer students at the University of Georgia. Athens, Georgia: Department of Adult Education.

Morin, E. (1996) Introducción al Pensamiento Complejo. España: Gedisa.

Pink, S. (2001). Doing Visual Ethnography. Londres: SAGE.

Reguillo Cruz, R. (1995). Pensar la ciudad desde la comunicación. En: Galindo, J. y Luna, C. (coords.). Campo académico de la comunicación: hacia una reconstrucción reflexiva (pp. 109-132). México: ITESO-Conaculta.

Segato, R. (2010). Las estructuras elementales de la violencia. Ensayos sobre género entre la antropología, el psicoanálisis y los derechos humanos. Buenos Aires: Editorial Prometeo.

Tilly, C. (2000). La desigualdad persistente. Buenos Aires: Editorial Manantial.

Valentine, G. (1993). (Hetero)Sexing Space: Lesbian Perceptions and Experiences of Everyday Spaces. Environment and Planning D: Society and Space, 11(4), pp. 395-413. Disponible en: [https://doi.org/10.1068/d110395].

Wade, P. (2008). Debates contemporáneos sobre raza, etnicidad, género y sexualidad en las ciencias sociales. En: Wade, P., Urrea Giraldo, F. y Viveros Vigoya, M. (Eds.). Raza, etnicidad y sexualidades. Ciudadania y multiculturalismo en America Latina. Bogotá. Universidad Nacional de Colombia, Centro de Estudios Sociales. 
Informate Salta (9 de marzo de 2018). \#8M: Salteños repudiaron las pintadas en las paredes de la ciudad. On line. Disponible en: [https:// informatesalta.com.ar/noticia/146361/8m-lagente-repudio-las-pintadas-en-las-paredes-dela-ciudad].

El Tribuno de Salta (10 de marzo de 2018). Las pintadas de la marcha del $8 \mathrm{~m}$ que invadieron el centro salteño. On line. Disponible en: [https:// www.eltribuno.com/salta/nota/2018-3-9-1736-0-las-pintadas-despues-de-la-marcha-del$8 \mathrm{~m}$-invadieron-el-centro-salteno].

DNI Salta (8 de marzo de 2018). Transmisión en vivo de la marcha del 8 de marzo. Facebook DNI Salta. Disponible en: [https://www.facebook. com/Dni.Salta.Dni/videos/1581039695350037/ UzpfSTE4MzMwNzA3ODQ6MTAyMTA0MzY3MzkyNzQ3ODc/]. 